\title{
Composition and safety of cured meats in the USA
}

\author{
Robert G. Cassens \\ University of Wisconsin, Muscle Biology Laboratory, Madison, Wisconsin 5370, USA
}

(Received 15 March 1996; revised version received 30 October 1996; accepted 30 October 1996)

\begin{abstract}
The meat-consuming public is concerned about foodborne illnesses which are primarily of microbiological origin, about more long-term effects thought to be associated with dietary consumption patterns, and about the possible presence of low levels of various additives or contaminants. Even though 100\% safety from foodborne illnesses can never be achieved, steady progress is being made through adoption of new technologies and improved control and prevention systems. A new generation of low-fat products gives the consumer more dietary choices, and modern cured meats have lower residual nitrite than they did twenty years ago. (C) 1997 Elsevier Science Ltd
\end{abstract}

\section{INTRODUCTION}

Albrecht and Pinkerton (1993) demonstrated that present-day consumers have an intense interest in health, especially as related to food consumption patterns and specifically to intake of meat. This has taken two courses which have impacted enormously on the meat industry.

First, there has developed an insistence on absolute or $100 \%$ safety for foods consumed. Obviously, as this goal is approached, the cost becomes prohibitive. Johnson (1989) has reiterated in detail the microbiological issues associated with meat. The problems associated with Salmonella spp and Listeria monocytogenes have been especially troublesome. More recently the organism E. coli $\mathrm{O} 157: \mathrm{H} 7$ has been of great concern, and Potter and Griffen (1983) have explained the epidemiological consequences. The industry has dealt with microbiological problems (Lahr, 1996) by constantly improving control and prevention systems, and examination of technologies such as irradiation, carcass rinses and steam vacuuming. A total revision of the meat inspection system in the USA has been proposed (Federal Register, 1996).

Second, as explained by Kritchevsky (1994), there has developed an enormous concern that certain dietary patterns are related to the insidious, long-term development of coronary heart disease and cancer. This concern impacts on the topic of this paper-cured meats. Two components of cured meat have come under withering attack. They are fat and nitrite. The distress about fat has been its possible association with diseases of the heart and circulatory system and also with a propensity for some forms of cancer. The result has been increased interest in and movement toward a more vegetarian type of diet, and the development and marketing of an entirely new generation of low-fat meat products. The nervousness about nitrite has centered on the potential link to cancer, and will be explained later in this paper.

\section{PROPERTIES OF MODERN CURED MEATS}

The usual process for manufacture of a cured meat is to incorporate salt, nitrite, a reducing agent (such as ascorbate) and other ingredients such as seasonings (Kramlich et al., 1973). The meat is heat processed (often with smoke) to a pasteurizing temperature, and then, frequently, packaged in a vacuum package. The result is a meat product with a characteristic pink color and specific flavor. Because of the curing ingredients, the heat processing and the usual use of vacuum packaging, the product will maintain freshness and safety for several weeks, assuming a proper refrigeration chain.

Composition of cured meats, especially emulsion products such as wieners and bologna, has changed greatly in the past decade (Cassens, 1997). The changes have been driven by consumer demand for low-fat products. While the allowable fat content of these products is basically $30 \%$, they have been altered so that products containing 1 to $5 \%$ are now commonly available. The fat content of fresh meat has also been lowered by production practices (McLarin \& Schultz, 1992) and retail trimming. Buege et al. (1990) surveyed the composition of retail pork cuts and compared the results with data given in Handbook 8-10 (USDA, 1983). They found, for example, that the mean fat content of raw separable lean from pork loin chops was 5 grams of fat per 100 grams of separable lean compared to 7.2 grams from Handbook 8-10. 
Miller (1993) studied the acceptability of low-fat meat products and found palatability of low-fat products was a problem area. Since fat provides a flavor component as well as a lubrication effect in regard to mouth feel, the reduction of fat level, especially if it is a drastic reduction, results in a perceivable change in flavor. Moreover, because the fat (removed in lowfat products) is replaced with water, the result is a softer texture. If the additional water is not satisfactorily bound, purge results, giving an unsightly appearance to the package (Keeton, 1994).

Several authors (Mandigo, 1991; Mandigo \& Eilert, 1994; Eilert et al., 1993) have written in detail about low-fat meat products. In the first instance, meat with less fat is used. This may extend as far as using meat which has been specifically treated to remove fat, resulting, for example, in a product such as partially defatted tissue. The other avenue of approach is an actual replacement of fat. Other proteins, either of animal or plant origin, may be used. More likely is the use of a carbohydrate such as a starch or gum. Another possibility is to use a synthetic compound which mimics the function of fat but does not provide calories to the consumer. Obviously, governmental regulations and labelling requirements must be complied with.

There are three resulting conditions of interest regarding low-fat cured meats, which might impact on safety (Cassens, 1997). The conditions are:

1. the meat block (component or amount) has been reduced substantially in some products and may contain poultry, and the ingoing amount of nitrite is based on the meat block;

2. a larger amount and greater variety of flavoring agents is being used;

3. some rather unusual components such as gums, plant proteins and high-connective-tissue meats are being used.

The question of interest regarding these substantial changes which have occurred in cured meats is how they have impacted on the chemistry of the nitrite used for curing. Little fundamental research has been done on this new generation of cured meats.

\section{KNOWLEDGE OF CURING MEAT WITH NITRITE}

For recent complete accounts of the process and outcome of nitrite curing of meat see Cassens (1990, 1995a).

While the use of nitrite and nitrate to cure meat is traced to antiquity, the process has been regulated in the USA, by the United States Department of Agriculture (USDA) since the early 1900s. Sodium nitrite is allowed to be added at a maximum of $156 \mathrm{ppm}(1 / 4$ ounce or $7 \mathrm{~g}$ per 100 pounds of meat). In current practice, nitrate is rarely used, and the maximum allowable amount of a reducing agent (ascorbate or erythorbate) is normally employed. The amount of nitrite used in practice may be less than the maximum allowed. Residual nitrite is the amount analytically detectable in the product and is considerably lower than the amount added (since it is reacted with or bound to constituents of the meat).

Curing results in a characteristic pink color (Fox, 1987) as well as distinct flavor and texture, which are well recognized by consumers (Cross \& Ziegler, 1965; Cho \& Bratzler, 1970). Importantly, a microbiological preservative effect is also achieved, and specific protection is provided against Clostridium botulinum (Perigo et al., 1967). This is especially important because many cured meats are in vacuum packages and the organism is an anaerobe.

Nitrite is a reactive chemical and must be used with caution. It is lethal to humans in a dose of approximately $1 \mathrm{~g}$ (Fassett, 1973). It acts as a nitrosating agent and under appropriate conditions produces nitroso compounds, some of which are specific and potent carcinogens. Nitrite is converted to nitric oxide, an active nitrosating agent which can react with secondary amines to form carcinogenic nitrosamines.

During the 1970s the safety of cured meats was strongly debated (see Krol \& Tinbergen, 1974). At issue was the question if preformed nitrosamines were present at all or at levels of concern and if the known levels of residual nitrite represented a risk to human health. The potential problem was recognized and dealt with by the meat processing industry. The use of nitrate was essentially eliminated, the levels of nitrite used were lowered and much tighter control of manufacturing processes was instituted. Ascorbate and erythorbate were used at maximum levels to inhibit formation of nitrosamines, and a nitrosamine monitoring program for bacon was commenced by USDA.

The National Academy of Sciences (NAS) studied the problem and issued two reports (National Academy of Sciences, 1981, 1982). The reports were a complete compilation of available information. Recommendations were made for minimizing any potential risk, and suggestions were made for future work. In view of the reports and the changes which had been made by the industry, it seemed that the perceived problem had been more or less solved.

But now, fifteen years later, concern has resurfaced. It was reported in the news media (Maugh, 1994) that'Children who eat more than 12 hot dogs per month have nine times the normal risk of developing childhood leukemia'. The claim was based on an epidemiological paper entitled 'Processed meats and risk of childhood leukemia (California, USA)' (Peters et al., 1994).

In order that a conclusion can be drawn about the seriousness of this potential risk, a summation follows regarding current and applicable knowledge about sources of nitroso compounds and the role of cured meats. 


\section{METABOLISM AND PHYSIOLOGY}

A complex situation is presented when nitrite and/or nitrate are ingested. The ingestion is usually associated with meals or drinking and is not a continuous type of infusion, there are species differences and the role of bacterial infection can be strong. The following pathway is now well-established for humans (Schuddeboom, 1993; NAS, 1981). Ingested nitrate is absorbed rapidly from the upper gastrointestinal tract, and the majority of it is eliminated in the urine. The average half-life for urinary elimination of nitrate is about $5 \mathrm{~h}$. Ingested nitrite may react with other substances in the gastrointestinal tract or, if it is absorbed into the circulatory system it is oxidized rather rapidly to nitrate. Nitrite in the blood may oxidize haemaglobin to methaemaglobin, thereby reducing or destroying the oxygen carrying ability.

Of great interest is the fact that a portion of the nitrate in the circulatory system is secreted by the salivary glands in humans but not in rats (Tannenbaum et al., 1974). The microbial flora of the oral cavity can reduce nitrate to nitrite, which is then consumed by swallowing. The process is apparently dose dependent. On a quantitative basis, the nitrate secreted by the salivary glands is about $25 \%$ of the nitrate ingested. About $20 \%$ of the salivary nitrate is reduced to nitrite. Therefore, about $5 \%$ of ingested nitrate is actually reduced to nitrite in the saliva and reconsumed as nitrite.

Another process of considerable significance is the endogenous synthesis of nitrate and nitrite in humans. A great deal of scientific effort was expended to reveal the situation, and especially the importance of synthesis within mammalian tissue as opposed to heterotrophic bacterial nitrification. It was established that endogenous synthesis of nitrogen oxides from reduced (e.g. ammonium) nitrogen in humans and other animals arose from mammalian and not bacterial origin. It is now known that the mechanism of this reaction is the enzymatic conversion of L-arginine to nitric oxide and that the nitric oxide may be converted to nitrite and nitrate and be excreted (see, for example Tannenbaum in Gongalli et al., 1994; Green et al., 1981; Leaf et al., 1989).

\section{SOURCES OF NITRITE, NITRATE AND N-NITROSO COMPOUNDS}

In order to control intake of these compounds by humans, the sources must be identified and understood. The importance of establishing baselines and conducting periodic tracking studies is obvious. Much current interest is focused on fertilizer use and the subsequent exposure of humans to nitrate from drinking water and certain leafy green or root vegetables. Exposure to nitrogen compounds in the environment is also of concern.

The National Academy of Sciences (1981) concluded that of dietary nitrite intake, $39 \%$ was from cured meat,
$34 \%$ was from baked goods and cereals and $16 \%$ was from vegetables. Hill (1991) published a review composed of several papers from various experts. A major overall conclusion was that nitrate in drinking water various enormously and is of great concern in some instances. A great amount of current data is provided by Schuddeboom (1993) in a work entitled "Nitrates And Nitrites In Foodstuffs'. The exposure to nitrite from intake of foods preserved with nitrite is low, but the intake of nitrate from drinking water may contribute considerably to the total body burden. Cornee $e t$ al. (1992) published information about French food products. The average daily nitrate intake per person per day was $121 \mathrm{mg}$ with $85 \%$ from vegetables, $5 \%$ from preserved and cured meat and 5\% from cereal products. The average nitrite intake per person per day was $1.88 \mathrm{mg}$ with vegetables supplying $43 \%$, cured meat $28 \%$ and cereals $16 \%$. Knight et al. (1987) of the UK found there was a mean intake from food of about $95 \mathrm{mg}$ of nitrate and $1.4 \mathrm{mg}$ of nitrite. Vegetables constituted over $90 \%$ of the nitrate intake and cured meats $65 \%$ of the nitrite intake. Drinking water added about another $13.5 \mathrm{mg}$ of nitrate to the daily intake. Gangolli et al. (1994) have published a risk assessment for nitrate, nitrite and $\mathrm{N}$-nitroso compounds as encountered in the human diet. Vegetables constitute a major source of nitrate providing more than $85 \%$ of the average daily human dietary intake. NAS (1981) reported the nitrate content (mg/kg fresh weight) as 2600 for beets, 1500 for celery and 1700 for lettuce.

There are recent results for residual nitrite content of cured meats in the USA. Cassens (1995b) found residual nitrite in retail product as $7 \mathrm{ppm}$ for bacon, $6 \mathrm{ppm}$ for sliced ham and $4 \mathrm{ppm}$ for hot dogs. In a larger survey involving nearly 100 retail samples of cured meats from various manufacturers, the preliminary result for overall mean of residual nitrite was $10 \mathrm{ppm}$ (Cassens, 1996). White (1975) used an average residual nitrite of $52.5 \mathrm{ppm}$ for his calculations of human intake of nitrite. The data he quoted for franks had a range of 0-195 ppm. It is quite obvious, therefore, that during the past 20 years a considerable decrease in residual nitrite in cured meats has occurred in the USA.

\section{NITRIC OXIDE}

One of the most active research areas in biological science, at present, is elucidation of the crucial and beneficial effects of nitric oxide in the human body (Culotta \& Koshland, 1992; Feldman et al., 1993). Nitric oxide has been discovered to be a biological messenger important in the physiological functions of neurotransmission, blood clotting, blood pressure control, and in the immune system's ability to kill tumor cells and intracellular parasites. It is now known that even though microorganisms can generate NO by reduction of nitrite or oxidation of ammonia the synthesis of NO is quite 
different in mammals where Nitric Oxide Synthase catalyzes the stepwise oxidation of the amino acid 1-arginine to NO and 1-citrulline. Stamler et al. (1992) have cautioned that the details of the biochemistry of nitric oxide remain poorly understood. Nitric oxide can be interconverted among different redox forms with distinctive chemistries, and the term NO neither adequately identifies its redox form nor delineates the chemical reactivity of nitrogen monoxide in biological systems.

\section{EPIDEMIOLOGICAL STUDIES}

Epidemiological results should be studied carefully because they may hold the key to answering some critical questions. However, such studies often result in dispute because one side concentrates on a potential and critical link between a result and identified causative factor while an opposing viewpoint points out all the other potential factors which have not been controlled.

Sarasua and Savitz (1994) studied the consumption of cured and broiled meat in relation to childhood cancer. Their analysis of results suggested that maternal consumption of cured and charcoal-broiled meats during pregnancy generally was not associated with an increased risk of childhood cancer; the exception to this was that hot-dog consumption was found to be associated with brain tumor risk. They also found that the associations between childhood meat consumption and cancer were stronger and more consistent than those seen in the maternal diet analysis. Acute lymphocytic leukemia was associated most strongly with consumption of hamburger. Brain tumors showed positive associations with childhood consumption of ham, bacon, and sausage, and hot dogs. The authors concluded that cured and charcoal broiled meats may be linked to childhood cancer, and that the subject, especially the observation about hot dog consumption by mothers and children, should be studied and evaluated further.

Peters et al. (1994) studied the relation between the intake of certain food items, thought to be precursors or inhibitors of $\mathrm{N}$-nitroso compounds, and the risk of leukemia in a case-control study among children from birth to 10 years in Los Angeles County, California. The food items of interest were: breakfast meats (bacon, sausage, ham); luncheon meats (salami, pastrami, lunch meat, corned beef, bologna); hot dogs; oranges and orange juice; and grapefruit and grapefruit juice. The only persistent associations were for children's intake of hot dogs and risk of leukemia. There was no evidence that fruit intake provided protection.

Bunin et al. (1994) reported a case-control study of maternal diet during pregnancy and risk of childhood brain tumor (astrocytoma). A trend was observed for consumption of cured meats, which contain preformed nitrosamine and their precursors. However, the authors did not observe strong trends for nitrosamine, nitrite, nitrate, vitamin $\mathrm{C}$ or vitamin $\mathrm{E}$. They did observe that interpretation of the results was difficult because the effect of several dietary factors differed by family income level. They concluded the results of the study provided limited support for the nitrosamine hypothesis (that $\mathrm{N}$-nitroso compounds and their precursors, nitrite and nitrate, are risk factors and vitamins $\mathrm{C}$ and $\mathrm{E}$, which inhibit $\mathrm{N}$-nitroso formation, are protective factors for brain tumors).

Two follow-up letters have expanded on the previous studies, in an attempt to provide some further explanation (Preston-Martin \& Lijinsky, 1994; Bunin, 1994). The thought has emerged that nitrite from cured meats, rather than total nitrite, is important. Nitrosamides are more important than nitrosamine for nervous system tumors. Finally, since vitamins $\mathrm{C}$ and $\mathrm{E}$ can block formation of $\mathrm{N}$-nitroso compounds, it is important to learn more about this in humans.

Mirvish et al. (1995) reported recently on the use of the N-nitrosoproline (NPRO) test to measure the potential for intragastric formation of carcinogenic nitrosamine in humans. Higher doses of nitrate produced more NPRO, and ascorbic acid inhibited NPRO formation.

\section{CONCLUSIONS}

The consuming public has become much more aware of, and concerned about, food safety issues associated with meat consumption, and these may be divided into two broad categories:

1. food borne illnesses which are primarily of microbiological origin; and

2. more long-term effects reputedly associated with dietary consumption patterns, and the possible presence of low levels of various additives or contaminants.

The interrelationships of cured meat, residual nitrite, $\mathrm{N}$-nitroso compounds and cancer was studied thoroughly during the decade of the 1970s. On balance it was concluded that there is little or no risk to humans from normal consumption patterns of cured meats.

Recent changes by the industry, in response to consumer demands, have resulted in a new generation of products. The major change has been a reduction in the fat content, in some cases to extremely low levels.

Recent epidemiological studies have reopened the question about a possible link between cured meat consumption and cancer, especially in children. However, analytical studies of modern cured meat have revealed a much lower residual nitrite as compared to twenty years ago (about $1 / 5$ as much). 


\section{ACKNOWLEDGEMENTS}

This work was supported in part by the College of Agricultural and Life Sciences, University of Wisconsin. Muscle Biology Laboratory manuscript number 348.

\section{REFERENCES}

Albrecht, J. A. \& Pinkerton, W. F. (1993). Food safety issues and communicating risk. Proc. 46th Annual Reciprocal Meat Conference. Lincoln, NE.

Buege, D. R., Held, J. E., Smith C. A., Sather, L, K. \& Klatt, L. V. (1990). A nationwide survey of the composition and marketing of pork products at retail. Univ. Wisconsin Research Bulletin R3509. Madison, WI.

Bunin, G. (1994). Cured meats and childhood cancer (Letters to the editor). Cancer Causes and Control, 5, 485-486.

Bunin, G. R., Kuijten, R. R., Boesel, C. P., Buckley, J. D. \& Meadows, A. T. (1994). Maternal diet and risk of astrocytic glioma in children: A report from the Childrens Cancer Group (United States and Canada). Cancer Causes and Control, 5, 177-186.

Cassens, R. G. (1990). Nitrite-cured meat: a food safety issue in perspective. Food and Nutrition Press, Inc., Trumbull, CT.

Cassens, R. G. (1995a). Use of sodium nitrite in cured meats today. Food Tech., 49, 72-81.

Cassens, R. G. (1995b). Current content of residual nitrite in cured meats at retail. Proc. 41 st Intl. Congress on Meat Science and Technol., San Antonio, TX.

Cassens, R. G. (1996). Residual nitrite in commercial cured meat in the USA: 1995. IFT Annual Meeting Abstract. New Orleans, LA.

Cassens, R. G. (1997). Residual nitrite in cured meat: USA 1996. Food Tech., 51, 53-55.

Cho, I. C. \& Bratzler, L. J. (1970). Effect of sodium nitrite on flavor of cured pork. J. Food Sci., 35, 668-670.

Cornee, J., Lairon, D., Velema, J., Guyader, M. \& Berthezene, P. (1992). An estimate of nitrale, nitrite, and $N$-nitrosodimethylamine concentrations in French food products or food groups. Sci. des Aliments, 12, 155-197.

Cross, C. K. \& Ziegler, P. (1965). A comparison of the volatile fractions from cured and uncured meat. J. Food Sci., 30, 610-614.

Culotta, E. \& Koshland, D. E. (1992). NO news is good news. Science, 258, 1862-1863.

Eilert, S. J., Blackmer, D. S., Mandigo, R. W. \& Calkins, C. R. (1993). Characteristics of low-fat frankfurters mannufactured with modified beef connective tissue. J. Muscle Foods, 4, 269.

Fassett, D. W. (1973). Nitrates and nitrites. In Toxicants occurring naturally in foods. Nat. Acad. Sciences. Washington, D.C.

Feldman, P.L, Griffith, O. W. \& Stuehr, D. J. (1993). The surprising life of nitric oxide. Chem. Eng. News, 71(51), 2638.

Federal Register (1996). Pathogen Reduction; Hazzard Analysis Critical Control Points (HACCP) Systems; Final Rule. Dept. Ag. FSIS. 9CFR, Part 340 et al., July 25, 1996, Vol 61, No. 144

Fox, J. B. Jr. (1987). The pigments of meat. In The Science of Meat and Meat Products (3rd edn), eds Price, J. F. and Schweigert, B. S. Food and Nutrition Press, Westport, CT.

Gangolli, S. D., van den Brandt, P. A., Feron, V. J., Janzowsky, C., Koeman, J. H., Speijers, G. J. A., Spiegelhalder,
B., Walker, R. \& Wishnok, J. S. (1994). Nitrate, nitrite and N-nitroso compounds. Europ. J. Pharmacol, 292, 1-38.

Green, L. C., de Luzuriaga, K. R., Wagner, D. A., Rand, W., Istfan, N., Young, V. R. \& Tannenbaum, S. R. (1981). Nitrate biosynthesis in man. Proc. Natl. Acad. Sci., 78, 7764-7768.

Hill, M. (1991). Nitrates and Nitrites in Food and Water. Ellis Horwood, I.ondon, UK

Johnson, J. L. (1989). Meat microbiological issues: known and unknown. Proc. Meat Ind. Res. Conf. AMI. Washington, D.C.

Keeton, J. T. (1994). Low-fat meat products. Technological problems with processing. Meat Sci, 36, 261-276.

Knight, K. M., Forman, D., Al-Dabaagh, S. A. \& Doll, R. (1987). Estimation of dietary intake of nitrate and nitrite in Great Britain. Food Chem. Toxicol., 5, 277-285.

Kramlich, W. E., Pearson, A. M. \& Tauber, F. W. (1973). Processed Meats. AVI Publishing Co. Inc. Westport.

Kritchevsky, D. (1994). Diet and health. Proc. 47th Recip. Meat Conf. University Park, PA.

Krol, B. \& Tinbergen B. J. (1974). (eds) Proceedings international symposium on nitrite in meat products. Pudoc. Wageningen, The Netherlands.

Lahr, J. (1996). Carcass microbial load expectations postslaughter. 49th Recip. Meat Conf. Provo, Utah.

Leaf, C. D., Wishnok, J. S. \& Tannenbaum, S. R. (1989). Larginine is a precursor for nitrate biosynthesis in humans. Biochem. Biophys. Res. Comm., 163, 1032-1037.

Mandigo, R. W. (1991). Problems and solutions for low-fat meat products. Proc. Meat Ind. Res. Conf. AMI, Washington, D.C.

Mandigo, R. W. \& Eilert, S. J. (1994). Strategies for reducedfat processed meats. In Low Fat Meats: Design Strategies And Human Implications, eds H. D. Hafs \& R. G. Zimbelman, Academic Press, New York, USA.

Maugh, T. H. II. (1994). Study links hot dogs, cancer. Washington Post, June 3.

McLaren, D. G. \& Schultz, C. M. (1992). Genetic selection to improve the quality and composition of pigs. Proc. Recip. Meat Conf. Fort Collins, CA.

Miller, R. K. (1993). Acceptability of low-fat meat products. Proc. Meat Ind. Res. Conf. AMI, Washington, D.C.

Mirvish, S. S., Grandjean, A. C., Reimers, K. J., Connelly, B. J., Chen, S., Gallagher, J., Rosinsky, S., Nie, G., Tuatoo, H.Payne, S.Hinman, C. \& Ruby, E. I. (1995). Dosing time with ascorbic acid and nitrate, gum and tobacco chewing, fasting, and other factors affecting N-nitrosoproline formation in healthy subjects taking proline with a standard meal. Cancer Epi. Biomarkers and Prevention., 4, 775-782.

National Academy of Sciences (1981). The health effects of Nitrate, Nitrite, and N-Nitroso Compounds. Natl. Acad. of Sci., Natl. Acad. Press, Washington, D.C., USA.

National Academy of Sciences. (1982). Alternatives to the current use of nitrite in foods. Natl. Acad. of Sci., Natl. Acad. Press, Washington, D.C

Perigo, J. A., Whiting, E. \& Bashford, T. E. (1967). Observations on the inhibition of vegetative cells of Clostridium sporogenes by nitrite which has been autoclaved in a laboratory medium discussed in the context of sub-lethally processed cured meats. J. Fd. Technol., 2, 377-397.

Peters, J. M., Preston-Martin, S., London, S. J., Bowman, J. D., Buckley, J. D. \& Thomas, D. C. (1994). Processed meat and risk of childhood leukemia (California USA). Cancer Causes and Control, 5, 195-202.

Potter, M. E. \& Griffin, P. M. (1993). The epidemiology of Escherichia coli O157:H7. Proc. Meat Ind. Res. Conf. AMI. Washington, D.C.

Preston-Martin, S. \& Lijinsky, W. (1994). Cured meats and childhood cancer (Letters to the Editor). Cancer Causes and Control, 5, 484-485. 
Sarasua, S. \& Savitz, D. A. (1994). Cured and broiled meat consumption in relation to childhood cancer: Denver Colorado (United States). Cancer Causes and Control, 5, 141-148.

Schuddeboom, L. J. (1993). Nitrates and nitrites in foodstuffs. Council of Europe Press, Belgium.

Stamler, J. S., Singel, D. J. \& Loscalzo, J. (1992). Biochemistry of nitric oxide and its redox-activated forms. Science, $\mathbf{2 5 8}$, 1898-1902.
Tannembaum, S. R., Sinskey, A. J., Weisman, M. \& Bishop, W. (1974). Nitrite in human saliva. Its possible relationship to nitrosamine formation. J. Nat. Cancer Inst., 53, 79-84.

USDA. (1983). Composition of foods. handbook 8-10. Pork prodcuts. raw, processed, prepared. Washington, D.C.

White, J. W. (1975). Relative significance of dietary sources of nitrate and nitrite. J. Agric. Food Chem. 23, 886-891 (see correction in J. Agric. Food Chem. 24, 202, (1976)). 